\title{
Time for the UK to commit to tackling child obesity
}

The UK government missed an opportunity for global leadership on child obesity. Now it's time to commit, say Mark Hanson and colleagues

\author{
Mark Hanson British Heart Foundation professor ${ }^{1}$, Edward Mullins specialty trainee year 6 in \\ obstetrics and gynaecology ${ }^{2}$, Neena Modi professor of neonatal medicine ${ }^{3}$
}

${ }^{1}$ Institute of Developmental Sciences, University of Southampton, Tremona Road, Southampton SO16 6YD, UK; ${ }^{2}$ Queen Charlotte's and Chelsea Hospital, Imperial College Healthcare NHS Trust, Du Cane Road, London W12 OHS, UK; ${ }^{3}$ Department of Medicine, Imperial College London, Chelsea and Westminster Campus, 369 Fulham Road, London SW10, UK,

The UK government published its report Childhood Obesity: $a$ Plan for Action, after a protracted delay, on 18 August 2016, when parliament was in recess and the nation was focused on the success of Team GB at the Rio Olympics. ${ }^{1}$ The plan received very little media coverage or public response. There was, however, an immediate outcry from the medical and public health communities, who had hoped for much more. ${ }^{2-6}$ The draft version had been 50 pages in length, but the published plan ran to just 10 pages; strong actions were conspicuous by their absence, and the desired discussion of anti-obesogenic medicine had been watered down to an emphasis on voluntary actions by industry, consumers, and schools.

One of the most important omissions was reference to the recommendations of the World Health Organization Commission on Ending Childhood Obesity (ECHO). ${ }^{7}$ The final ECHO report, published in January 2016, was the culmination of about 18 months of evidence review and wide consultation. It was presented at the World Health Assembly in May 2016, ${ }^{8}$ where a decision was made to request the director general to develop an implementation plan to guide further action on the recommendations, in consultation with member states. The implementation report is now available. ${ }^{9}$

\section{A missed opportunity for global leadership}

The ECHO report directs specific actions and responsibilities to governments of member states (box 1). By not referring to it in the obesity report, the UK government missed an opportunity to show global leadership in child health by announcing advance commitment to implementing some of the ECHO commission's recommendations-for example, an industry levy on sugar sweetened beverages, nutrient profiling to identify healthy and unhealthy foods, clearer food labelling, and promotion of physical activity in schools. Other recommendations, such as stronger controls on advertising, mandatory food reformulation, and nutrition education were absent from the report.

In June 2016, while waiting for the UK government to publish its report on child obesity, an international group of researchers, policy makers, and representatives of research funders, professional organisations, and WHO met at St George's House, Windsor Castle, under the aegis of the Royal College of Paediatrics and Child Health and the University of Southampton. The group discussed effective action to combat childhood obesity, nationally and globally. This paper arose from that discussion.

\section{What's missing from the government's plan?}

Overweight and obese children are likely to remain so as adults, ${ }^{10}$ when they will be at greater risk of non-communicable diseases such as type 2 diabetes, cardiovascular disease, some cancers, asthma, and other atopic conditions. ${ }^{11}{ }^{12}$ The economic consequences of child overweight and obesity relate not only to direct healthcare costs ${ }^{13}$ but to a range of indirect healthcare costs extending across the life course and reducing longevity. The government's plan notes the short and long term damage to the health of individuals from obesity, but it fails to recognise that overweight and obesity in children and young people are driven by multiple modifiable biological, behavioural, environmental, and commercial factors, some of which operate before conception and birth. ${ }^{14}$ Nor does it recognise that the harm extends across generations. This failure represents a major lost opportunity for effective prevention.

Many communities typically affected by undernutrition are now experiencing overnutrition through changes in diet, sedentary lifestyles, and a lack of focus on promoting broader health. In these settings, the adverse health effects of poor maternal health and childhood stunting are amplified by the increased risk of later overweight and obesity. ${ }^{15}$ Furthermore, the rising 


\section{Box 1: Implementing the ECHO report-actions and responsibilities for member states}

Take ownership, provide leadership, and give a political commitment to tackling childhood obesity in the long term

Coordinate contributions of all government sectors and institutions responsible for policies, including, but not limited to: education; food and agriculture; commerce and industry; development; finance and revenue; sport and recreation; communication; environmental and urban planning; transport and social affairs; and trade

Ensure data collection on body mass index for age of children, including ages not currently monitored, and set national targets for reductions in prevalence of childhood obesity

Develop guidelines, recommendations, or policy measures to engage relevant sectors-including the private sector where applicable-to implement actions aimed at reducing childhood obesity

prevalence of maternal obesity and gestational diabetes is driving childhood obesity in the next generation. ${ }^{16}$ Such problems are particularly acute in lower socioeconomic and educational attainment groups - those least equipped to meet the challenge. The government's plan mentions the marked association between socioeconomic adversity and childhood obesity but not the steps necessary to tackle this growing inequity.

Interventions that might improve unhealthy trajectories initiated during early development are largely based on evidence from animal research ${ }^{17}$ or observational studies and small randomised controlled trials in humans. ${ }^{18}$ This is partly because some interventions can't feasibly be randomised (for example, breast feeding) but also because outcomes are difficult to evaluate a long time after the intervention. In addition, reliable markers of risk of obesity are scarce. The government's plan does not mention the necessity for strategic programmes of research and evaluation to strengthen the evidence base for population level interventions. The delegates at St George's House thought it would be helpful for the scientific and political communities to agree on approaches to define interim policies for intervention based on existing evidence, and their robust evaluation, so that they can be fully accepted, modified, or rejected as appropriate.

The concept that obesity prevention is predominantly a matter of personal or parental responsibility has been particularly unhelpful. Infants and young children are wholly vulnerable to the actions of adults and to the broader societal factors that create an obesogenic environment, including the marketing practices of industry. For older children and young people, and their parents, a sole focus on personal responsibility is likely to result in guilt, resistance, denial, and perpetuation of the problem. Voluntary actions, ranging from people trying to lose weight to industry developing healthier products, have so far been ineffective in halting the rise in obesity, so the government's emphasis on personal choices and voluntary measures by industry is especially disappointing. Fiscal and regulatory measures, such as taxes and regulations on the marketing and packaging of cigarettes, have brought enormous benefits to child and population health; governments should not hold back from taking such actions to protect children.

Healthcare professionals alone are not adequately positioned and do not have the resources to tackle this multifactorial, societal problem that spans government, industry, education, and the public. ${ }^{1920}$ Additionally, healthcare in the adolescent and preconception periods; contraception; pregnancy planning; antenatal, pregnancy, and postpartum care; and child health are often fragmented and under-resourced. Other professionals such as nursery staff and school teachers, community pharmacists, health visitors, social workers, and dentists could assist in generating the wider cultural movement needed, especially in engaging hard-to-reach groups such as migrants and those with lower educational or socioeconomic attainment.

\section{What can we do now?}

Measures to tackle factors associated with childhood obesity that would benefit individual health, even though a causal relationship may be uncertain, should be put in place immediately. Surprisingly the government's plan doesn't mention any of these factors, which include avoiding parental smoking, reducing high pre-pregnancy body mass index, avoiding excessive gestational weight gain, and encouraging breast feeding. ${ }^{21} 22$

Children have different metabolic set points depending, in part, on the intrauterine environment in which they develop. So a focus confined to calorie restriction or physical activity will give variable, and often disappointing, results. Weight and body mass index are easy indices to measure, but people are likely to appreciate a focus on health and fitness rather than just weight, and this may allow more nuanced and positive messages to be conveyed to the public. The government's intention to promote physical activity is excellent, but it will be insufficient in isolation; the public, parents, children, and young people need education to improve nutrition literacy and awareness of the benefits of physical activity regardless of weight.

Constructive discourse with the private sector is essential to developing an effective response to the societal challenge of overweight and obesity in children and young people. The approach of national governments and international agencies has been inconsistent in its relations with industry, and some public health communities have resisted such engagement. Multinational corporations operate across national jurisdictions, so we need a wider global approach in which clinical, professional, and scientific organisations have a potentially powerful contribution to make. Engagement with industry needs to take into consideration trade issues and how to manage conflicts of interest. Engaging with industry may not be possible for organisations such as WHO, but the implementation plan for ECHO commits to developing guidelines for engaging with the private sector in consultation with member states. ${ }^{9}$

\section{Let's create a global alliance}

Individual and population health are the fundamental capital of society. We need to recognise this and make the development of evidence informed policies to promote healthy development in infants, children, and young people a national and international priority. This links clearly to the sustainable development goals, ${ }^{23}$ which offer an unprecedented opportunity for global collaboration and action. Lack of action to tackle childhood obesity goes against the United Nations Convention on the Rights of the Child (Article 24), which recognises "the right of the child to the enjoyment of the highest attainable standard of health," and, given the substantial economic costs of overweight and obesity, is counter to national economic wellbeing.

We do not know why the UK government reneged on delivering the promised and much needed strategy, but we do know that 
the value of investing in long term population health is often compromised by the short term focus of politics. We need ongoing advocacy and leadership by groups independent of governments and the development of approaches that recognise the necessity for a life course approach to achieving health across generations. The St. George's House group recommended an initiative comprising relevant legislation, an accountability framework, sustained public engagement, and global advocacy campaigns, underpinned by research and evaluation and led by professional bodies, academic societies, and research institutes. Action is needed across five sectors: education, healthcare, government, industry, and the public. A coordinated approach would involve not only top down provision of resources to assist behaviour change in the sectors of the population most at risk but also bottom up creation of demand. Engaging young people is crucial in all sectors, as they will be the parents of tomorrow and can be agents of change. ${ }^{24}$

Healthcare professionals are respected by the public and other professionals and have direct reporting mechanisms to governments. They have existing, well organised professional bodies that routinely cooperate within and across nations. We therefore propose creation of a new initiative to coordinate between these sectors - a global alliance against child obesity led by an international alliance of healthcare organisations (box 2). This alliance would be ideally placed to liaise with other bodies for which this area is a priority, such as WHO, ${ }^{79} \mathrm{FIGO},{ }^{25}$ and the Lancet Early Child Development Series group. ${ }^{26} \mathrm{We}$ hope that the UK government would work with the alliance to build on their plan for action and develop it into a strategy for childhood and future societal health.

We thank Sarah Brown for giving the opening address at St George's House on 2 June 2016 and thank St George's House, the Royal College of Paediatrics and Child Health, and the University of Southampton for financial and logistic support.

Competing interests: We have read and understood BMJ policy on declaration of interests and declare that NM is president of the UK Royal College of Paediatrics and Child Health. The other authors have no interests to declare.

Contributors and sources: This article arose from a discussion at St George's House, which was attended by UK government officials and the following named delegates: Alain Beaudet, Olly Buston, Judith Ellis, Peter Gluckman, Anne Greenough, Mark Hanson, Sandra Hassink, Philip James, Anne Johnson, Lindsay Keir, Berthold Koletzko, Navjoyt Ladher, Shoo K Lee, Joe McNamara, Neena Modi, Edward Mullins, Lucilla Poston, Lesley Regan, Nigel Rollins, John Savill, Sebastian Taylor, Russell Viner, Jyotsna Vohra, Juana Willumsen, and Paul Zimmet. All attendees contributed to the discussion. AB, PG, AG, MH, NM, EM, LP, NR, ST, JW contributed to the authorship of this analysis. $\mathrm{MH}, \mathrm{EM}$, and $\mathrm{NM}$ wrote the article. MH is the guarantor of the article.

We thank Sarah Brown for giving the opening address at St George's House on 2 June 2016 and thank St George's House, the Royal College of Paediatrics and Child Health, and the University of Southampton for financial and logistic support.

Provenance Not commissioned; externally peer reviewed

1. HM Government. Childhood obesity: a plan for action. August 2016. https://www.gov.uk government/uploads/system/uploads/attachment_data/file/546588/Childhood_obesity_ 2016_2_acc.pdf.

2 Boseley S. Childhood obesity: UK's 'inexcusable' strategy is wasted opportunity, say experts. Guardian 2016 August 18. https:/www.theguardian.com/society/2016/aug/18/ childhood-obesity-strategy-wasted-opportunity-campaigners.

3 Royal College of Paediatrics and Child Health. RCPCH responds to "weak" child obesity plan. http://www.rcpch.ac.uk/news/rcpch-responds-weak-child-obesity-plan.

4 Knai C, Petticrew M, Mays N. The childhood obesity strategy. BMJ 2016;354:i4613.pmid: 27562654 .

5 UK government won't step up to the plate on childhood obesity. Lancet2016;388:841.

6 Lobstein T. McPherson K. Nothing new in UK's strategy on childhood obesity. Lancet 2016:388:853-4 doi:10.1016/S0140-6736(16)31471-4 pmid:27597454.

7 World Health Organisation. Report of the commission on ending childhood obesity. 2016 http://www.who.int/end-childhood-obesity/final-report/en/

8 World Health Assembly decision WHA69(12) 2016

9 WHO. Report of the Commission on Ending Childhood Obesity: implementation plan. Report by the Secretariat for the 140th Session of the WHO Executive Board. http://apps. who.int/gb/ebwha/pdf files/EB140/B140 30-en.pdf.

10 Craigie AM, Lake AA, Kelly SA, Adamson AJ, Mathers JC. Tracking of obesity-related behaviours from childhood to adulthood: A systematic review. Maturitas 2011;70:266-84. doi:10.1016/j.maturitas.2011.08.005 pmid:21920682.

11 Reilly JJ, Kelly J. Long-term impact of overweight and obesity in childhood and adolescence on morbidity and premature mortality in adulthood: systematic review. Int J Obes (Lond) 2011:35:891-8. doi:10.1038/ijo.2010.222 pmid:20975725.

$12 \mathrm{Ng} \mathrm{M}$, Fleming T, Robinson M, et al. Global, regional, and national prevalence of overweight and obesity in children and adults during 1980-2013: a systematic analysis for the Global Burden of Disease Study 2013. Lancet 2014;384:766-81. doi:10.1016/ S0140-6736(14)60460-8 pmid:24880830.

13 Pelone $F$, Specchia ML, Veneziano MA, et al. Economic impact of childhood obesity on health systems: a systematic review. Obes Rev2012;13:431-40. doi:10.1111/j.1467-789X. 2011.00968.x pmid:22212590.

14 World Health Organisation. Consideration of the evidence on childhood obesity for the Commission on Ending Childhood Obesity. 2016. http://apps.who.int/iris/bitstream/10665/ 206549/1/9789241565332_eng.pdf?ua=1.

15 Hanson MA, Gluckman PD, Ma RC, Matzen P, Biesma RG. Early life opportunities for prevention of diabetes in low and middle income countries. BMC Public Health 2012;12:1025.pmid:23176627.

16 Ma RC, Chan JC, Tam WH, Hanson MA, Gluckman PD. Gestational diabetes, maternal obesity, and the NCD burden. Clin Obstet Gynecol 2013;56:633-41. doi:10.1097/GRF. 0b013e31829e5bb0 pmid:23820121.

17 Poston L, Taylor PD, Nathanielsz P. Influences of maternal obesity on the health of the offspring: a review of animal models. In: Obesity, ed. $M W$ Gillman and L Poston. CUP, 2012: 100doi:10.1017/CBO9780511782466.011.

18 Waters E, de Silva-Sanigorski A, Hall BJ, et al. Interventions for preventing obesity in children. Cochrane Database Syst Rev 2011;(12):CD001871.pmid:22161367.

19 Redsell SA, Atkinson PJ, Nathan D, Siriwardena AN, Swift JA, Glazebrook C. Preventing childhood obesity during infancy in UK primary care: a mixed-methods study of HCPs knowledge, beliefs and practice. BMC Fam Pract 2011;12:54. doi:10.1186/1471-229612-54 pmid.21699698.

20 Story MT, Neumark-Stzainer DR, Sherwood NE, et al. Management of child and adolescent obesity: attitudes, barriers, skills, and training needs among health care professionals. Pediatrics 2002;110:210-4.pmid:12093997.

21 Robinson SM, Crozier SR, Harvey NC, et al. Modifiable early-life risk factors for childhood adiposity and overweight: an analysis of their combined impact and potential for prevention. Am J Clin Nutr 2015:101:368-75. doi:10.3945/aicn.114.094268 pmid:25646335.

22 Gillman MW, Ludwig DS. How early should obesity prevention start? N Engl J Med 2013;369:2173-5. doi:10.1056/NEJMp1310577 pmid:24224559.

23 United Nations. Sustainable development goals. http://www.un.org/ sustainabledevelopment/sustainable-development-goals/

24 Department of Health. Chief Medical Officer annual report 2014: women's health. 2014. www.gov.uk/government/uploads/system/uploads/attachment_data/file/484383/cmoreport2014.pdf.

25 Hanson MA, Bardsley A, De-Regil LM, et al. The International Federation of Gynecology and Obstetrics (FIGO) recommendations on adolescent, preconception, and maternal nutrition: “Think Nutrition First". Int J Gynaecol Obstet 2015;131(Suppl 4):S213-53.pmid: 26433230.

26 Britto PR, Lye SJ, Proulx K, et al. Nurturing care: promoting early childhood development. Lancet 2017;389:91-102.pmid:27717615.

Published by the BMJ Publishing Group Limited. For permission to use (where not already granted under a licence) please go to http://group.bmj.com/group/rights-licensing/ permissions 


\section{Box 2: Suggested roles of a global alliance against child obesity}

Emphasise the need for a life course approach to prevent overweight and obesity to safeguard the health of individuals, populations, and future generations

Advocate for a "whole society" approach to wellbeing that recognises the importance of multi-sector engagement extending beyond healthcare

Champion the concept that the preconception period constitutes an important opportunity for engaging future parents in interventions to prevent obesity and promote health, providing "three for one" leverage in economic terms

Push for effective training of a wide range of health and education professionals in how to engage parents, children, and young people with the issue of overweight and obesity

Formulate a set of key questions around preventive measures and methods of implementation for which a national or international guideline might be justified; approach WHO or other agencies to establish a systematic review group to answer these questions

Set key research priorities in relation to basic science, healthcare, and societal interventions that target infancy and the preconception period; approach funders to commission research in these areas and catalyse partnerships to deliver studies

Broker dialogue between industry, policy makers, scientists, educators, professional bodies, and children and young people

Campaign for government actions on relevant policies, regulation, fiscal actions, and investment

\section{Key messages}

Preconception, gestational, infancy, and childhood factors contribute towards a trajectory of poor childhood and lifelong health, overweight, and obesity

The UK government's action plan for childhood obesity has been published but is severely limited

It could be considerably strengthened by incorporating further evidence based interventions recommended in WHO's ECHO report

To achieve the $\mathrm{ECHO}$ recommendations, healthcare professionals should use their national and global professional networks to coordinate action between sectors including education, industry, government, and the public. 